\title{
Flat Affect, Joyful Politics and Enthralled Attachments: Engaging with the Work of Lauren Berlant
}

\author{
Robbie Duschinsky • Emma Wilson
}

Published online: 4 December 2014

(C) Springer Science+Business Media New York 2014

One of today's major theorists, Lauren Berlant, has explored the diverse cultural registers across which sense and feeling organise public and private life from sexual and aesthetic experiences to political participation and economic struggles. She considers how these zones of practice fit together: for instance, how the aesthetics of embodiment and eating relate to the temporality of the workday and the debt cycle; how what is unbearable or unclear in our fantasies and experiences of intimacy open onto modes of political discourses of nationhood, citizenship and identification; how investments in the image of the innocent child across popular screen media and political rhetoric are animated by the fantasy of the unhumiliated citizen. These are domains with which we are all fiercely concerned in all their uncertainty, urgency and capacity to surprise. As Cavell (1979, p. 84) has observed, "in everyday life the lives of others are neither here nor there; they drift between their inexpressiveness and my inaccuracy in responding to them". Berlant's work has tracked this drift; as Stewart (2012, p. 367) has observed, "Berlant's legacy is a labor of attending to emergent forces in the course of the ordinary, attuning to the agitations of a subject troubled by the world's potential for event, and culling the current precarity of life itself into a new object of analysis".

We agree with Stewart that there is something utterly remarkable and incisive about Berlant's approach, which attends to genre as a cluster of promises, a scene of feeling and sensing which sheds light on the organisation, the delight and difficulties of everyday living. For Berlant, a "genre" is an emotionally invested, patterned set of expectations about how to act and how to interpret, which organises a relationship between the acting and interpreting subject, their feelings and impressions, their struggles and their historical present. Genres also organise conventions about what might be hoped for, explicitly or secretly, and the bargains that can be made with life. Genres serve as mooring, or placeholders, for intensities within streaming experience. Their conventions give a place and pacing to - and thereby partially hollow out - the discrepancies and the possibilities which occur within the constitution of a particular form of feeling subject. In doing so, they provide the terms for a confirming

R. Duschinsky $(\bowtie)$

Social Work and Communities, Northumbria University, Coach Lane Campus, Newcastle upon Tyne, Tyne and Wear NE77XA, UK

e-mail: robert.duschinsky@northumbria.ac.uk

E. Wilson

Department of French, Corpus Christi College, Trumpington Street, Cambridge CB2 1RH, UK

e-mail: efw1000@cam.ac.uk 
reciprocity in the subject's encounters with others and with her or himself, hinging an image of the public and private.

Though it has kinship with the more familiar sociological notion of a "norm" (Thurborn 2002), the concept of genre has the advantage of highlighting the dialectic of fictional and lived forms in which each animates and transduces the expectations and energy of the other. The concept also highlights that the glitches and gaps on the way to reproducing conventions are not exceptions, but the warp and woof of our plots and practices. Indeed, it is precise that these provide the content to genres enacted within fiction, as they offer the resolution and lack of resolution of our everyday struggles:

Even the prospects of failure that haunt the performance of identity and genre are conventional: the power of a generic performance always involves moments of potential collapse that threaten the contract that genre makes with the viewer to fulfil experiential expectations. But these blockages or surprises are usually part of the convention and not a transgression of it, or anything radical. They make its conventionality interesting and rich, even (Berlant 2008, p. 4).

In Berlant's formulation, genre is how we organise the heterogeneity of sensation and experience so that we can each have a day and manage its demands and intensities and drabness in a way that retains a sense of meaningfulness and continuity, as well as a balance between cruising along and exploring what might be possible. In contrast to theorists such as Agamben and Badiou, who oppose the regulatory norm to the exception in a way which sometimes threatens to reify both, Berlant is careful in her treatment of the relationship between convention, feeling, uncertainty and injustice. This care finds her considering how normality is not only a site of hegemonic convention, but, for many, serves as a felt aspiration, as a response to the difficulties they face in getting by materially, emotionally, socially and keeping breathing as best as they can. In the chapter "Nearly Utopian, Nearly Normal" of Cruel Optimism, for example, Berlant considers the pared-down aspirations of those who experience "the historical present as a scene of constant bargaining with normalcy in the face of conditions that can barely support even the memory of the fantasy" (Berlant 2011a, p. 167). These aspirations, she observes, are "a mode of living-on with the dread of an eternal present that gets drowned out by the noise of promised normativity's soothing bustle" (Berlant 2011a, p. 180).

Berlant's analyses attend to the variety of practical and relational advantages that can accrue from "riding the efficiency of the norm" (2014, p. 110) and to the ways our relational encounters within an expected frame, with others or by ourselves, can sustain us and make us brave, as well as threaten us or render us callous. She is attentive to how costly it might be to stretch or open patterns of living beyond those facilitated by available genres and forms of institutional scaffolding, including that of law and social policy. She is concerned, therefore, with the role of fantasy as a ballast for stabilising the ambivalence that we have towards both existing genres of living and also other modes which we can imagine or into which we might be compelled by events. Belant documents the ways in which, in small moments as well as at times of higher intensity and contradiction-whether at the touch of intimacy or disaster- "one flails around wanting something other than what is, but one also fears the disappointment of one's lack of imagination and trust in the patience and inventiveness of others" (2014, p. 110).

Berlant's two great objects of sustained analysis are love and citizenship, scenes of investment which she considers powerfully tied together within contemporary biopolitics, though her work has engaged sustained consideration of other issues including law, embodiment, gender, pain and historical time. In the domain of love, genre suggests to us the relevant 
possibilities for how to enact being a member of a family or a partner or a friend, what the relationship might aspire to and its members daydream about, what modes or degree of feeling of possession is permitted and the degree to which this tie should feel central or peripheral to the solidity of a sense of self. Genres of love mark out established paths for how to feel about, for instance, the potential for intimacy with or loss of the loved person and what to do with those feelings. They mark out what are the relative distribution of expectations and responsibilities when one is struggling to manage one's sense of need-or, indeed, one is becoming overwhelmed - and also the occasions in which becoming somewhat dysregulated by desire, or anger, or grief is precisely what is expected. They mark the points at which one might feel worried about being too greedy for affection or of being someone not capable of eliciting love in others.

Conceptualising love as organised by genres, in Berlant's sense, allows for a nuanced attention to the difficulties and possibilities of relationality for subjects who have been excluded from authorised forms of living or who have only been able to access intelligible forms and spaces for confirming reciprocity at a certain price or in some pared-down version. It also allows her to ask precise questions about the relationship between genre and politics, offering the term "juxtapolitical" to refer to the way that sentimental plots open towards certain visions of politics whilst refusing or operating below the marked status of political (Berlant 2008 , p. 3). Through this lens, she analyses "the use of the logic of romantic desire to neutralize, at least symbolically, the violence and attraction at play in hierarchical social relations implicitly suggests that structures and institutions of power can always be overcome by personal feelings, personal choices" ([2000-2002] 2012, p. 108). Such precise questions about genre and politics are animated by consideration of those who find themselves endangered or diminished by the forms of relationality which appear available to them. Considering the position of queer subjects in relation to genres and laws which define public morality and meaningful private intimacy in ways which privilege love lived within a heterosexual couple or family, Berlant observes that "it is hard not to see lying about everywhere the detritus and the amputations that come from attempts to fit into the fold; meanwhile, a lot of world-building energy atrophies" (1998, p. 286), and yet, she suggests:

Rather than hate the couple form or love the couple form, say "here's what being in a couple can do, and here's the other things I need in order to flourish." Then you start to think of yourself as having a capacity to produce many kinds of patterning and attachment to the world. The problem is always that queer life is exhausting because you kind of have to make it up all the time. There are so few conventions to rest in or cruise in. At the same time, it's also really exciting to think you could be inventing something that will work better than the forms of efficiency that we call normative (Berlant 2013).

Whereas feeling and sensing are all too often treated as natural given within discussions of politics, their consideration through the aesthetic lens of genre directs attention both to the ways in which they are trained and the occasions of dysregulation or discrepancy which attend their enactment within everyday life. The specific discrepancy which most interests Berlant is the double-bind within which fantasies of belonging can themselves threaten or exhaust the material and affective conditions for substantive belonging and our flourishing together. As well as a detailed analysis of love, the contradiction of autonomy and belonging which forms "America" as the target of affective investments and an integral component within many genres in the USA and worldwide is a second, integral case for this analysis. "The fantasy of the American Dream", she argues, "is an important one to learn from": 
A popular form of political optimism, it fuses private fortune with that of the nation: it promises that if you invest your energies in work and family-making, the nation will secure the broader social and economic conditions in which your labour can gain value and your life can be lived with dignity... [Yet] for this paradoxical feeling to persist, such that a citizen of the Dream can feel firmly placed in a zone of protected value while on the move in an arc of social mobility, the vulnerability of personal existence to the instability of capitalism and the concretely unequal forms and norms of national life must be suppressed, minimised, or made to seem exceptional, not general to the population (Berlant 1997: 4)

Exploring specific genres which enact such suppression, Berlant has considered forms of discourse and representation — about 9/11 for example (Berlant 2005)—which scaffold politics as a mass-mediated scene in which the private, consuming individual comes to feel attached to a public experience by the feelings which appear shared between private and collective life. Berlant terms the result an "intimate public", a public sustained through an apparent commonality of sentiment. The disjuncture between the affective participation in the public and the concrete enactment of privatised, consuming individuality operates a rhythm in the lives of its citizens, galvanising an "abstract political fulfilment" in the dream of intimacy and collective feeling whilst undermining the conditions for material belonging in the present (Berlant 1991, p. 217). She has also considered genres of lived and fictional practice which service the tensions of this dream in managing the hopes and disappointments of autonomy and belonging which tie the citizen to the state. Berlant's The Queen of America Goes to Washington City (1997) is a study of tales of pilgrimages made by citizens to the metropole in order to re-find the polis and the order of their symbolic and affective relation to it. Berlant has also studied the image presented by Barak Obama of a community obligated to care for one another based on "hope", exploring how this discourse holds at arms' length, without fully neglecting, an engagement with class in American society (Berlant 2011b).

Deploying what she has sometimes termed a "realist account of fantasy", Berlant emphasises that the solidity and sense of our social and political infrastructures - whether nations, publics, labour markets or heteronormative regulations and conventions - are held afloat by specific constellations and economies of affective investments. In turn, affective investments are anchored for the subject by institutions and modes of injustice. These investments organise the stakes of our activity and shape what possibilities we consider to be meaningful in play. As a result, when pressure is placed on the infrastructure of social life or it is forced to change, genres of fantasy must likewise undergo some kind of alteration. For example, as there have become too few hours in the day to satisfy the demands of the labour market and retain a satisfying relational life, what has expanded has not been time or money, but our investments in fantasies regarding the future (Berlant 2010). Through such analyses, Berlant's work marks a major development of Marxist theories of ideology and an advance on Foucault's work on subjectivation. Marxist theory, most incisively in the work of the Frankfurt School, identified that human beings can willingly commit ourselves to patterns of living which deplete us and our possibilities. Foucault developed this insight in his treatment of the institutional and discursive apparatuses through which these patterns of living are suggested or imposed and the forms of power/knowledge through which they attain legitimacy. Berlant's great contribution is to trace the promises made by these patterns of living which make them experientially inhabitable and desirable for the subject.

One term she has for the quality of subject-positions which render them minimally inhabitable is "the metric of survival" (2011a, p. 4). Berlant's deployment of a language of survival has received criticism from Lee Edelman, who describes a "suspicion of rhetorics that 
privilege viability or survival" since the resources for generating an intelligible and authorised future, particularly in relation to family life, are so unevenly distributed (Berlant and Edelman 2014), yet this criticism perhaps does not adequately recognise that Berlant is not valorising any survival as such. Instead, the language of "survival" marks out the object of a tender but critical analysis: Berlant is interested in the constellation of conventions and affects which formulate a particular life, with its struggles, incoherences and contingencies, as offering sufficient sweetness to warrant inhabitation, even if there is little taste of this in the present. This concern with the promises which innervate subject-positions ultimately is an evaluative position, establishing a frame within which questions can be asked about what the good life might look like now in contrast to the minimally inhabitable forms of life which are supported by our institutions and imaginations. "Survival looks like a triumph", Berlant says, "and that's a terrible thing. I want flourishing" (Berlant and Hardt 2011).

In presenting such an analysis, Berlant's goal is not to mock or pop our investments and modes of fantasy — as if they were primarily enjoyments offered in lieu of meaningful and political agency — as, for example, is the tendency of Slavoj Žižek. Instead, Berlant attends to the contexts which move subjects to find reason for optimism within particular practices, objects or encounters in order to render their lives both experientially and materially survivable. She does so with sympathy for the hopes and difficulties which may power this movement even as she considers the ways in which they can hurt or isolate the subject from others or from themselves. "What are the technologies of patience that enable subaltern people to seem to consent to, or to take responsibility for, their painful contexts?", she asks (Berlant 1997, p. 222). In this, she diverges from analyses which treat all cultural forms and forms of living as ultimately able to be boiled down to the same material or psychical processes; her approach is resolutely concerned to pick out the specific economy and constellation of feeling and sense which organises particular forms of acting and experiencing.

This approach attunes Berlant's work to the specificities as well as the historical continuities of contemporary neoliberal discourse in imagining the relationships of autonomy and belonging in linking the citizen to the nation. Within this discourse, it is through entrepreneurial autonomy and the avoidance of dependency that one participates in the ideal of the nation and receives some authorised sense of belonging, yet to maintain dependency as something that only ever happens to other people mercilessly strains and wears subjects physically and emotionally, eliciting new cultural and lived modes of tension and testimony. In particular, established expectations of what can be hoped or bargained for from oneself, others and the state must be disappointed and reimagined:

The Euro-American state is a cowardly lion, a weeping bully, a plaintive lover to finance capital. It cannot bear to admit that, having grown its own administrative limbs to serve at the pleasure of the new sovereign of privatized wealth, that the wealthy feel no obligation to feed the state. So the state bails out banks and tells the polis to tighten up, claiming that the people are too expensive to be borne through their state, which can no longer afford their appetite for risk. They are told that they should feel shame for having wanted more than they could bear responsibility for and are told that they should take satisfaction in ratcheting down their image of the good life and the pleasures to be had in the process of its production. The affective orchestration of the crisis has required blaming the vulnerable for feeling vulnerable; not due only to a general precarity but also to the political fact that there is no longer an infrastructure for holding the public as a public (Berlant 2010).

In this context, one significant response is to replenish and intensify fantasies of national and personal autonomy, reinvesting in genres which string fantasies of belonging, modes of 
pragmatic practice and cynicism and authorised optimistic affects (e.g. "ambition" and "responsibility") in order to service market processes and accumulation. Berlant's account suggests that this response will also likely reinvest in a fantasy of family life, as a form naturally endowed with the capacity to manage all that living throws at its members and as an emotional counterweight to the atomism of economic exploitation. Another possible response is to accept crisis as a repetition of the disappointments with oneself or with the world which have already been accepted as evidence that nothing will ever change and that collective political efforts are meaningless. This path at least offers some relief in that it allows the subject to step off from ravaging expectations of personal resilience and inexhaustibility, which have been situated as the necessary response to an austerity politics which offers no reliable net or resting place from market pressures and outcomes.

Capitulation and resignation are far from the only available responses, however, though they set out salient poles of contemporary response. Among this variety, Berlant attends to ways of conceptualising openings for political solidarity. She finds these openings in the struggles of the subject to seal themselves into an acceptable privacy and participate within an authorised, ideal public. In contrast to theorists who deride or dismiss genres of cultural production and of living within convention as false consciousness, she allies herself with the gaps, improvisation and self-estrangement which these forms produce and thinks through them to consider how ways of living in our society might be made more just, more generous and patient. In some cases, this leads Berlant to attend to the way that some intensities of feeling and modes of embodied life explode out of convention for a time (even if they end up with a sense of loss or a form of social sanction). However, in other cases, Berlant tracks the small awkwardness, the important ill-fit, of scenes and gestures which stretch or open the kinds of affective investment and imaginary a subject is capable of enacting, but which might be so fleeting that a subject who lived through them might not even remember them by the end of the day. Berlant treats such cases as little laboratories for experimenting with how a more capacious, less fragile form of living might be structured, more than survival, and what the good life might look like.

The goal of this treatment is to explore what infrastructures and imaginaries might support forms of life in which thriving and solidarity and a bit of beauty can be part of ordinary existence rather than pieces of a fantasy projected into the future and never concretely lived or, minimally, to explore what might support forms of life in which subjects experience less violation and isolation by the conditions of their life, opening some breathing space to envisioning alternate possibilities for relationality, for fantasy and for responding to injustice. For Berlant, it is not simply that the little laboratories within ordinary life can be read as prophesies or signposts for personal-political change. It is also that no substantial change occurs at any level without a serious disruption of the terms of living which had supported a certain competence within the prior arrangement of things; as such, as well as a politics of demonstrations and of collective action, there is also a necessary politics in leaning the dimensions and parameters of living with incompetence, awkwardness and explosion. For Berlant, opportunities for change emerge in "discovering and inhabiting disturbances in the relation between one's affects and one's imaginaries for action. That discovery is the site of potentially recontextualising creativity" (Berlant and Edelman 2014, p. 89).

We are thrilled to begin this special issue with a text by Berlant which develops her thought in an important direction, elaborating her interrogation of how we might fight or detach ourselves from the affective investments and practices which organise genres of living. "Structures of Unfeeling" considers Scott Heim's 1995 novel and Gregg Araki's 2004 film Mysterious Skin and develops a new concept, "flat affect", for thinking the possibility of resisting dominant genres of sense and feeling. The term itself is not an original coining, but an 
appropriation. Whilst the use of the term "flat" to describe a felt state goes back a long way further ("How weary, stale, flat, and unprofitable seem to me all the uses of this world!" Hamlet, Act 1, Scene 2), the phrase flat affect comes from psychiatric discourse. It has been used from the 1950s to the present in drawing a subtle, at times artificial, distinction between the symptoms of schizophrenia and depression (e.g. Arieti 1955; Keefe and Harvey 2010). Flat affect within this psychiatric discourse refers to an expressionless presentation; whereas a depressed patient might look sad, flat affect is a kind of emotional opacity in which affective display, in the face in particular, has little range, intensity and mobility, and subjectively, it is not clear to the patient what the feelings they experience mean or what bearing they may have for them. Berlant's take on the term extends far beyond this.

Berlant treats Mysterious Skin as exemplary of a cluster of queer and independent docudramatic narratives, which first emerged during the 1980s and which continue into the present. She identifies that the distinctive style which characterises these narratives is their underperformance of emotion, deploying the term flat affect for this underperformance. The genre of practice picked out by Berlant with the term flat affect occurs on the horizon of previous conventions for the display or non-display of feelings - such as deadpan, as a mode of rhetorical delivery which solidified in the late $1920 \mathrm{~s}$ - but presents a distinctive formulation of, and disruption to, the series event-sense-apprehension-response. Within these narratives, subjects encounter situations and incidents which would conventionally bring about forms of experience and relating which mark an event as significant, yet in these cases, there is something muted about the subject's response, and the meaning of this underperformance of emotion is not made clear.

One possibility which our genres of interpretation and imagination supply to make sense of this flat affect is that it is the consequence of trauma or emotional dispossession and of political or psychological circumstances which have disturbed the psychological scaffolding for having feelings commensurate with the intensity of experience. Berlant does not dismiss this account, but considers that there might be other reasons for affectively reticent practices which are rendered somewhat opaque to the injunctions of melodramatic, normative emotional performance. It might be a degree of reserve from situational injunctions, which carves out some affective and relational — indeed, some ethical—room for manoeuvre or apprehension. The withheld or uneven accessibility between self and other which is operated by flat affect stresses the difficulty in tying down gesture to a particular historical moment and a particular meaning within a set of conventions. As such, it has particular appeal at a historical moment in which subjects and collective movements feel a sustained crisis in their ability to make effective and consistent claims on the world, particularly in relation to politics but also in terms of intimate relations - this leaves things rather apprehensively suspended. The withheld or uneven accessibility of the subject of flat affect can disturb and reflect disillusionment with contemporary discursive forms - ranging from talk shows to pillow talk - which ask that we seek the truth of a subject and participate in a sense of belonging with them through the intensity of the private feelings and vulnerabilities that they make available.

For Berlant, a key part of the significance of flat affect as itself a genre of symbolic practice is that it focuses attention on the ways in which events can be sensed, holding at bay or dilating the conventions which would quickly find an established and closed form into which perceptions can be drained. In one regard, this aligns Berlant's account of flat affect with Žižek's concept of "interpassivity". For Žižek (2006), interpassivity is the process through which the responsibility to have feelings about something can get passed off by the organisation of a cultural form, for instance, where a film allows the viewer to sit back and relax because they know that the protagonist is feeling enjoyment on their behalf. Berlant appreciates the concept of interpassivity because it recognises that a lower intensity of affect than convention might 
expect is not necessarily the result of trauma or of an unwillingness or inability to properly engage and that such understated behaviour might have a pattern and logic to it which marks it as significant for thinking about issues such as politics or freedom. However, Berlant resists any implication that flat affect necessarily, or even generally, occurs in lieu of the subject taking responsibility for their feelings and perceptions. She emphasises that we would do well to avoid coming too quickly to any overread interpretation of the body that's unforthcoming in its affects, especially given that what counts as being affectively unforthcoming is a judgement suffused by historically situated fantasy and convention and power. An example of flat affect which is not interpassive is given by Berlant when she emphasises that biopolitical systems of supremacy disproportionately enjoin both compulsory affects and responsibility for managing them upon less privileged populations. In such a context, flat affect might serve as a mode of affective agency, not or not solely a substitute for it.

For Berlant, the expression of affect is a particular site within human relationality since expression denotes the register of vulnerability in the social. Since affect is the register of the felt and embodied intensity that we feel as ever subject to one another, flat affect occurs on the horizon of our expectations of sensed and situated encounter. There are so many occasions in which subjects feel the need to be circumspect or careful in showing the heterogeneity of feelings because of the spectre of threat or loss or unbearable uncertainty, as the punishment for incorrectly or inopportunely displayed affect. As Berlant identifies in her reading of Mysterious Skin, the performance of unqualified positive affect is enjoined with particular intensity by both contemporary genres of intimacy and by the smiley faceness of the service economy. Standing in stark contrast is the work of the actress Tilda Swinton described by Jackie Stacey in her article as the "Mistress of Flat Affect". Stacey emphasises the deep social and political significance of cinema for Berlant, who identifies the integral role of film in shaping the fantasy landscapes which structure the everyday lives of modern subjects. Stacey particularly highlights the significant role of cinematic narrative conventions in supporting the formation of modern constructions of femininity in which women and their affects are positioned as both the cause of trouble for male protagonists (prompting the tension which animates the story) and as the reward these protagonists receive for resolving these problems. The article treats an aspect of Swinton's work, her engagement in styles of underperformance of emotion within particular films, as engaged in a dialogue with these narrative conventions regarding femininity which are embedded both in the history of cinema and in our lives (allowing reflection too on Berlant's engagement with narratives of the feminine). In the dialogue sustained by Swinton's performance with established genres of performing a gender, the assumptions and organisation of these genres - for instance, everyday conventions and fantasies which formulate heterosexual seduction as acquisition - are disturbed in what they assume about men and women.

Berlant (1997, p. 86) has argued that "gender categories are best seen as spaces of transformation, nodal points that are supposed to produce general social intelligibility while encrusted with constantly changing noncoherent meanings". Stacey finds that Swinton's performance tests the emergent possibilities of genres of conventional femininity as they undergo transformation. Stacey draws from conversation with Berlant a sense of Swinton's performance as less a blend of gender signifiers than an experimental speculation on the limits of gender identity that generates a sense of setting something in motion. Stacey considers how Swinton's performances, in the constellation of conventions they enact and disturb by invoking signifiers without cohering them into a recognisable gender identity, direct attention to the historicity of these conventions, to the necessary role of improvised, present enactment in approximating and reinventing them in order to convey them from the past to the future. In particular, Swinton's performance of flat affect directs attention to the dominance of popular 
genres in which the availability to the viewer of the private, interior affects of a woman are the condition of her legibility and acceptability as a feminine subject. In her roles which involve cross-dressing, she does not "pass" as a man by adopting the signifiers of masculinity and neither does she fit existing genres of trans identity or tomboy play. Instead, Stacey reads Swinton as operating a living index of the difference that the gender of a subject is understood to make in terms of what affects and availability are to be anticipated in their relations with others and themselves.

In contrast to genres which cast femininity as highly expressive of affect, perhaps to the point of excess, Swinton's expressive response to events is underperformed, yet in doing so, her performance does not thereby drain into a different, easily legible alternative. She does not perform "repressed emotion" or "restrained feeling", both familiar expediencies of genres of feminine performance, but neither does she enact a masquerade of flat, suave masculinity. Her performance operates in a mode of unavailability to the expectations of the viewer; she does not fully depart from norms of conventional femininity, but neither does she remain fully faithful to them. Sometimes, this affective unavailability fits with and contributes to her position as the villain of the story, appearing as a lack of empathy as in Bong Joon-ho's Snowpiercer (2013). It has led to widespread characterisations of Swinton as somehow "alien" or "otherworldly" in the way that she departs from the terms of what the historical present considers possible within human relationality. Her deployment of flat affect can, however, be used to signify precisely her humanity and capacity for empathy, as in The Deep End (McGehee and Siegel 2001) in which the devotion of Swinton's character to her son is registered as a capacity to contain, to hold in reserve, the urgent feelings evoked by events without this performance draining out into generic conventions of feminine self-sacrifice.

Flat affect, then, is poles apart from any concept of the absence of sense and feeling. Instead, it allows sense and feeling a degree of protection from their translation and depletion into established genres for interpreting the world. In Michael Hardt's contribution to the special issue, he considers the way in which being affected by others is a power, not a weakness but a strength since it is apiece with our capacity to lock into and act in the world. In relation to flat affect, this account would emphasise that what appears on the body and face as a surprisingly weak expression might be the visible sign of a preservation and fidelity to a sense or feeling or occurrence in its specificity-its texture and tone, its points of access and departure, its aftertaste, the points of hardness or ill-fit or contradiction where it somewhat resists convention - the condition of its integration or coaxing or cultivation into forms which stretch or exceed existing genres of imagination and practice. Hardt identifies that in considering being affected as a mode of power, Berlant's work has important parallels with the ideas of Baruch Spinoza, especially as interpreted by Gilles Deleuze and by Antonio Negri. For both Berlant and Spinoza, the capacity to engage sense and feeling gauges a capacity to really be in the world and to register its heterogeneity, liveliness and available span.

Hardt draws out that since the capacity of others to affect us is so much greater than our capacity to affect ourselves, the attempt to engage sense and feeling as effective force must be a relational activity. It is through discovering and taking seriously disturbances and contradictions between one's embodied affects and the existing genres of being with others that the relationship between self and the world becomes somewhat untied and open to being reknotted into new genres of imagination and practice. This process does not much look like the sovereign choices which neoliberal discourse situates as the site of autonomy and freedom, as choice and contract as the means of regulating encounters and experiences. There is no unity inhabiting the process of untying and reknotting, only the uncertain connecting and coordinating an ensemble of necessarily relational elements in order to sustain some greater capacity to be affected and to act in the world. The power to be affected as we really are, Hardt argues, 
is filled with affects that are complex and contradictory and requires the engagement of a complex relation within and between feelings, imagination and practice at both personal and institutional levels.

As Deleuze ([1968] 1990, p. 311) writes in his interpretation of Spinoza, the "power of imagining things according to the affections they produce" is also equivalent to "a power of suffering". Hardt likewise emphasises that Berlant is well aware that this process of untying and reknotting is an uncertain one and can be painful, detrimental and ugly. It can leave one vulnerably off-centre, with all the disadvantages as well as possible advantages of that point of entry into the everyday. Hardt offers the helpful metaphor that increasing our power to be affected and thus enlarging our sphere of interactions has the same effect as shooting more arrows at a target while blindfolded: It increases our chance of an effective act. He distinguishes between engaging the processes which can increase our power to be affected and act and what he terms "a political project": The latter requires a focus on understanding, engaging and selecting among affects in imagining and putting the good life into practice together with others. The question of what counts as "properly political" is a matter that Hardt and Berlant have debated elsewhere (Berlant 2011c). The point here, however, is that both agree that there can be a great deal of strength and ease in convention, and this can be helpful where the conventions direct action within and towards one's vision of the good life. For Hardt and Berlant, the struggle is not per se with the conventions into which affects drain, but with how to discover means within, with and beyond convention of repeating or prolonging those affects with others which are joyful and preventing those which are detrimental (see also Berlant and Hardt 2011). In thinking through the possibility of a joyful politics, Hardt presents the intriguing image of Spinoza in the role of therapist. Against therapeutic approaches which support the client's autonomy and self-control, in Hardt's imagination, Spinoza would encourage his client to enlarge the scope and scale for joyful encounters with others in their lives and then to regularise a consistent relation with the situation or person(s) in order that the encounter can be repeated or sustained and make new things possible. Hardt gives the example of an intellectual engagement which helps a person to think with greater clarity and power than they could have done before; Spinoza, as therapist, would prescribe the formation of a stable relation with this source of intellectual joy, making the encounters repeat and last.

Hardt acknowledges that composing or decomposing relationships is ferociously complicated and ever unstable, and he lauds Berlant's work as of primary importance for its insights into the relational, aesthetic and ethical dimensions of the contradictory affects which animate this complexity and instability. Spinoza's attention to this domain has offered the concept of fluctuatio animi. Fluctuatio animi is the counterpart process, in the domain of affect, of confusion and doubt in the domain of the imagination. Fluctuationes animi "for the most part arise from an object which is the efficient cause of each affect. For the human body is composed of many great individuals of different natures, and so, it can be affected in many great different ways by one and the same body. On the other hand, because one and the same thing can be affected in many ways, it will also be able to affect one and the same part of the body in many different ways. From this, we can easily conceive that one and the same object can be the cause of many and contrary affects" (Spinoza [1677] 1994: II, 154, S). The final article of this special issue, by Robbie Duschinsky, Monica Greco and Judith Solomon, considers this conflict and complexity between affects in the child's early relationship with their familiar caregiver, putting contemporary research in developmental psychology on infant attachment into conversation with the ideas of Berlant and of Judith Butler.

For Butler, the human infant is dependent on their familiar caregiver and predisposed to seek him or her when alarmed as a source of protection and organisation in the world, even when this caregiver is themselves cruel or frightening. The alarmed infant looking for 
protection from such a caregiver is situated by Butler as the condition and mirror of the adult political subject who emerges practically and affectively beholden to a normalising and potentially punitive culture and political institutions. Butler considers attachment through the lens of Foucault's notion of "disciplinary power", which pins an individual to their identity and sets up pressures and punishments so that they will regulate and normalise themselves. However, she expresses concern that Foucault offers no adequate account of the affects of family life and that the term "attachment" requires further scrutiny and consideration as a tool for social theory. Berlant agrees that "one attaches to the world, or not, not in the mode of decision or emotion, but thrown into architectures of trust that are built from within in the process of being in life (including from desperation when there are no reliable anchors for trust)." (Berlant 2011c, p. 687). However, unlike Butler, Berlant argues that not all subjection operates through attachment, and she calls for more attention to the boundaries and shape of attachment processes; she refers back to Bowlby and to empirical attachment research in considering the meanings and value of the concept of attachment in amongst contemporary use of the term as an "ideologeme" (Berlant 2011a, b, c, p. 449).

Berlant has described that "to read with is to cultivate a quality of attention to the disturbance of [an] alien epistemology" (2014, p. 125). Duschinsky, Greco and Solomon attempt to "read with" developmental psychology and contemporary queer theory together. They set out to respond to Butler's call for more scrutiny of attachment as a tool for progressive thought, and Berlant's emphasis that the concept can both serve as an ideologeme and potentially support analysis of the relationship between affect and domination. In terms of the role of attachment as an ideological formation, they critically analyse British social policy since 2010, which has invoked attachment as support for austerity politics. The image of a selfsufficient mother and child at the base of the self-standing citizen has been deployed as rhetorical ammunition against social security and welfare supports. However, they also argue that attachment is not reducible to its construction. They argue that attachment processes do direct infants to imagine their caregiver as a self-sufficient sovereign: individualised, given meaning by past experience, and expected to manage incompatible feelings and relations. The familial relations of love and trust into which attachment injects us can be important for our investments from early childhood in modes of disciplinary power and can guide a tendency to accept and return to punitive and depleting conditions of life.

However, Duschinsky et al. draw together ideas about attachment from developmental psychology and the work of Berlant to contend that the child is more than the product of their attachments and that their attachments offer a surprising excess of labile affect which allows each of us to alter the terms of our enthrallment, representing and changing the terms established within our early relationships and subjection to cultural forms. Beyond early childhood, new possibilities may arise or can be made which can help us respond creatively, mutually and politically when impelled by a tendency to seek safety in a milieu which does not support flourishing or does so at a too high price. In this, the attachment disposition to find a safe base from which to explore does not need to be a clarion for a conservative focus on security as mere protection and individual responsibility but can serve as a spur to finding bases for working for change together without expectations of harmony or wholeness, a more expansive security and/as exploration.

The articles here have ventured out to consider quite different objects: the gender performance of Tilda Swinton, the guidance of Spinoza as therapist for a joyful politics and the progressive possibilities of attachment research. Each has been supported and organised by Berlant's insights into how people maintain lives in environments which deplete them and which run counter to their flourishing and the ways that these lives sometimes get compelled into or open onto different configurations. Berlant (Berlant 2011a, b, c, p. 4) offers the term 
"impasse" to describe "a stretch of time in which one moves around with a sense that the world is at once intensely present and enigmatic, such that the activity of living demands both a wandering absorptive awareness and a hypervigilance that collects material that might help to clarify things". We have found that engaging with the work of Berlant helps enter us into impasse: into sensitivity, apprehension, reflection and imagination. Her ideas gift a common conceptual space and set of questions which are responsive and organising for work which aims to be attentive to the role of feeling and desiring subjectivity in structuring our present in its politics and culture and forms of everyday living. Engaging with the work of Lauren Berlant as a common conceptual space for attuning to the movement of contemporary forces, in Emerson's words, leaves one "glad to the brink of fear".

\section{References}

Arieti, S. (1955). Interpretation of schizophrenia. NY: Robert Brunner.

Berlant, L. (1991). The anatomy of national fantasy: Hawthorne, Utopia, and everyday life. Chicago: University of Chicago Press.

Berlant, L. (1997). The Queen of America goes to Washington City essays on sex and citizenship. Durkham: Duke University Press.

Berlant, L. (1998). Intimacy. Critical Inquiry, 24(2), 281-288.

Berlant, L. (2005). "The epistemology of State emotion" in Dissent in Dangerous Times, ed. Austin Sarat Ann Arbor MI: University of Michigan Press, pp. 46-78.

Berlant, L. (2008). The female complaint: The unfinished business of sentimentality in American culture. Durham: Duke University Press.

Berlant, L. (2010). "Affect and the politics of austerity" Variant Magazine 39/40, accessed at: http://www.variant. org.uk/39_40texts/berlant39_40.html.

Berlant, L. (2011a). Cruel optimism. Durham: Duke University Press.

Berlant, L. (2011b). Opulism. South Atlantic Quarterly, 110(1), 235-242.

Berlant, L. (2011c). A properly political concept of love. Cultural Anthropology, 26(4), 683-691.

Berlant, L. (2013). "Interview with Lauren Berlant" Society \& Space, accessed at: http://societyandspace.com/ material/interviews/interview-with-lauren-berlant/.

Berlant, L., \& Edelman, L. (2014). Sex, or the unbearable. Durham: Duke University Press.

Berlant, L. \& Hardt, M. (2011). "On the risk of a new relationality", Reviews in Cultural Theory, accessed at: http://reviewsinculture.com/special-issue/reviewl.html.

Berlant, L. ([2000-2002] 2012). Desire/Love, NY: Punctum Books.

Cavell, S. (1979). The claim of reason. Cambridge: Harvard University Press.

Deleuze, G. ([1968] 1990). Expressionism in philosophy: Spinoza, trans. Martin Joughin, NY: Zone Books.

Keefe, R., \& Harvey, P. (2010). Understanding schizophrenia. NY: Free Press.

McGehee, S., \& Siegel, D. (2001). The deep end. USA: i5 Films.

Spinoza, B. ([1677] 1994). Ethics, trans. Edwin Curley, London: Penguin.

Stewart, K. (2012). Pockets. Communication and Critical Cultural Studies, 9(4), 365-368.

Thurborn, G. (2002). Back to norms! On the scope and dynamics of norms and normative action. Current Sociology, 50(6), 863-880.

Žižek, S. (2006). How to read Lacan. London: Granta Books. 